\title{
Power Management in Microgrid Through PV System
}

\author{
Ameerul A. J. Jeman, Naeem M. S. Hannoon, and Sharon S. Gerang
}

\begin{abstract}
This paper presents a performance comparison of real and reactive power flow in microgrid through PV system using both controller which are Fuzzy logic based and Conventional controller. In general, an electrical power management is an electronic system that provides detail information about the power flow in a distribution generation system or power substation. The PV system has two major problems; namely, low conversion efficiency of electric power generation and the amount electric power generated by solar array changes continuously. Therefore, the objective of this paper is to analyse the controller performance of conventional controller and the proposed one. The early work in fuzzy control was motivated by a desire to directly express the control actions of an experienced human operator in the controller and to obtain smooth interpolation between discrete controller outputs. Conventional controllers are simple and easy to understand but it is not very efficient due to presence of non-linearity in the system while fuzzy controllers have proper actions like human control actions, needs less data storage and more robust. The PV system will be simulated by using MATLAB/Simulink respectively. The results of the controller performance will be presented and compared with similar cases. Based on the results that are going to be obtained, a better performance in the fuzzy controller than the conventional controller is expected.
\end{abstract}

Index Terms-Power Management, Photovoltaic System, Microgrid, Fuzzy Controller, Real and Reactive Power, Simulink

\section{INTRODUCTION}

$\mathrm{G}$ enerally, an electrical power management system is an electronic system that provides comprehensive power flow information in an electrical generation or power substation network. This system provides data on power systems and related events and tracks them. The information is used to control efficiencies such as power generation, batteries, condenser banks, gas or steam turbine relays and other devices in power plants and power substations [1].

The concept of Microgrid (MG) refers to a Load and Distributed Generation (DG) cluster operating as a controllable entity that supplies electrical power to its nearest region [2]. MG is applied to address the interconnected question of separate DGs in carious power systems. The DG systems are decentralized and near the load.

This manuscript is submitted on $17^{\text {th }}$ April 2020 and accepted on $14^{\text {th }}$ September 2020. Ameerul Aiman Jeman, Naeem M.S Hannon and Sharon Serenade Anak Gerang are with the Faculty of Electrical Engineering, Universiti Teknologi MARA, 40450 Shah Alam, Selangor (e-mail: ameerulaiman94@gmail.com)

1985-5389/C 2021 The Authors. Published by UiTM Press. This is an open access article under the CC BY-NC-ND license (http://creativecommons.org/ licenses/by-nc-nd/4.0/)
Power management in MG taking into account the impact of continuous solar irradiance variations combined with load power variations [3]. Usually, DG systems use renewable energy sources such as wind, solar and biomass, which play a major role in the delivery of electricity [4]. The integration of energy distribution sources and controllable loads within the distribution network are part of the energy management challenges. Solar energy is the renewable energy source used in this project.

Solar energy is inexhaustible and one of the most promising renewable resources for mass production. Photovoltaic (PV) cells are the basic technology for converting solar energy into electrical energy [5]. However, PV generation has a major instability for the MG, which presents many challenges for power management, such as system stability, electrical power balance and failures. Also, the fluctuation in the power output of renewable energy sources will lead to excess voltage and fluctuations in the grid frequency [6]. It is very important to study the overall performance of the system in the gridconnected mode of operation with different types of loads on the distribution system.

Several studies regarding Conventional Controller and Fuzzy Logic Controller on PV system have been investigated over for the past years. The Conventional Controller is one of the most common controller used in the industrial control system. The only discrepancy that the controller measures between the measuring signal and the order signal or fixed point value. In both software and hardware, Conventional Controllers are simple, easy to understand and implement and do not require a process model for initialization or operation. However, due to the non-linearity of the device, Conventional Controller is not very effective [7]. Conventional Controller is fixed-gain feedback that unable to adapt in changes of the environment [8]. Conventional Controller also unable to provide a proper and great results as stated by [9].

FLC are widely used in various industrial processes to take appropriate measures, such as human control actions. FLC includes a number of parameters to be selected and configured beforehand. The FLC is derived from the fuzzy set theory in which the transition between membership and non-membership can be graded. Therefore, the boundaries of fuzzy sets can be indistinguishable and undefined, making them useful for approximate structures [9]. Reference [10] declared that the FLC have a better performance compared to Conventional Controller as it has a good performance when the atmospheric condition is changing. Based on studies by $[11,12]$, FLC does not require mathematical models or any extra hardware as it is easily adaptive to current PV system. FLC also has a simple 
design compared to Conventional Controller [11, 13]. The tracking performance of FLC is more accurate and faster speed in steady state performance $[12,14]$. FLC is an adequate solution for cases in nonlinear system tuning [13, 15]. FLC also valid for its redundancy, consistence and completeness [16]. Unfortunately, the FLC has its downfall such as the difficulty, high cost, instability and complexity of the controller [17].

\section{DYNAMIC MODEL OF PV MODULE}

Electromagnetic radiation of solar energy can be directly converted to electricity through photovoltaic effect. Photons with energy greater than the band-gap energy of the semiconductor, which is exposed to sunlight, creates certain electron-hole pairs equal to the frequency of radiation [18].

$I_{L}$ is the current source, represents the cell photocurrent. Rsh and Rs are the inherent shunt and series resistances of the cell. The value of Rsh is typically very large compared to Rs, which is very small, so it may deteriorate to simplify the analysis.

PV modules that are grouped together by larger units of PV cells are further interconnected in a parallel-series arrangement to form PV arrays. The equations of photovoltaic panel model are given in (1)- (6).

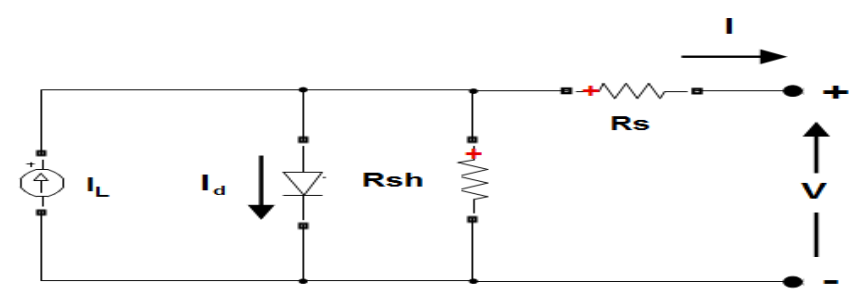

Fig. 1. Photovoltaic Circuit

The equivalent circuit of a PV cell is as shown in Fig. 1. The equation for this equivalent circuit is formulated using Kirchhoff's current law for current I.

$$
I=I_{L}-I_{D}-I_{S H}
$$

$I_{L}$ represents the light-generated current in the cell, $I_{D}$ represents the voltage-dependent current lost to recombination, and $\mathrm{I}_{\mathrm{sh}}$ represents the current lost due to shunt resistances. In this single diode model, $I_{D}$ is modeled using the Shockley equation for an ideal diode:

$$
I_{D}=I_{0}\left[\exp \left(\frac{V+I R_{S}}{n V T}\right)-1\right]
$$

Where $n$ is the diode ideality factor (unit less, usually between 1 and 2 for a single junction cell), $I_{0}$ is the saturation current, and $V T$ is the thermal voltage given by:

$$
V_{T}=\frac{K T_{c}}{q}
$$

Where $\mathrm{k}$ is Boltzmann's constant $\left(1.381 \times 10^{-23} \mathrm{~J} / \mathrm{K}\right)$ and $\mathrm{q}$ is the elementary charge $\left(1.602 \times 10^{-19} \mathrm{C}\right)$.
Writing the shunt current as $I_{s h}=\frac{V+I R_{S}}{R_{S h}}$ and combining this and the above equations results in the complete governing equation for the single diode model:

$$
I=I_{L}-I_{0}\left[\exp \left(\frac{V+I R_{S}}{n V T}\right)-1\right]-\frac{V+I R_{S}}{R_{s h}}
$$

Where:

$\mathrm{I}_{\mathrm{L}:}$ : Light Current(A)

$\mathrm{I}_{0}$ : Diode Reverse Saturation Current(A)

$\mathrm{R}_{\mathrm{s}}$ : Series Resistance $(\Omega)$

$\mathrm{R}_{\mathrm{sh}}$ : Shunt Resistance $(\Omega)$

$n$ : Diode Ideality Factor

Saturation current $I_{0}$ varies with the cell temperature, which is given by:

$$
I_{0}=I_{r s}\left(\frac{T}{T_{r}}\right)^{3} \exp \left[\frac{q * E_{g 0}}{B k}\left\{\frac{1}{T r}-\frac{1}{T}\right\}\right]
$$

The current output of PV module is

$$
\begin{aligned}
I_{P V}= & N_{P} \times I_{P H}-N_{P} \times \\
& I_{0}\left[\exp \left\{\frac{q \times\left(V_{P V}+I_{P V} R_{S}\right)}{N_{S} A k T}\right\}-1\right]
\end{aligned}
$$

The elementary unit of the PV system is a PV cell, regardless of utilization. The output voltage of a single PV cell is low (around 0.5 volts). Thus, in pragmatic application, these basic units are combined in number of parallel cells $\left(N_{P}\right)$ and series cells $\left(N_{S}\right)$ to obtain the output current $\left(I_{P V}\right)$ function of the PV array, as mentioned:

$$
I_{P V}=N_{P}\left[I_{p h}-I_{r s}\left(\exp ^{\propto V_{P V}}-1\right)\right]
$$

Where:

$\mathrm{q}=1.602 \times 10^{-19} \mathrm{C}$

$$
\alpha=\frac{\mathrm{q}}{\mathrm{Ns} \times \mathrm{T} \times \mathrm{k} \times \mathrm{a}}
$$

$\mathrm{k}=1.38 \times 10^{-23} \mathrm{~J} / \mathrm{K}$

$I_{p h}$ is photo current, generated by photon insolation is derived as:

$$
I_{p h}=0.01 \times G_{X}\left[I_{S C}+k_{i}\left(T^{*}-T\right)\right]
$$

Where $\mathrm{G}$ is called as insolation Watt $/ \mathrm{m}^{2}$ and $k_{i}=0.015$.

Reverse saturation current $\left(I_{r s}\right)$ of the diode from the equivalent circuit of PV cell is estimated as shown:

$$
I_{r s}=I_{r r}\left(\frac{T}{T \cdot}\right) \times \exp \left[\frac{q \times E_{g}}{k \times a}\left(\frac{1}{T}-\frac{1}{T \cdot}\right)\right]
$$


Where $E_{g}$ is band gap energy of the semiconductor material of the cell.

Derivative of PV power by the voltage is equal to zero. Accordingly, at the maximum power point:

$$
\begin{aligned}
\frac{d P_{p v}}{d V_{p v}}= & N_{p}\left[I_{p h}-I_{r s}\left(V_{p v} \times \exp ^{\propto V_{P V}}+\exp ^{\propto V_{P V}}\right.\right. \\
& -1)]=0
\end{aligned}
$$

The step size $\left(O_{V}\right)$ is reduced and accurate the tracking as it reaches nearer to the MPP point:

$$
O_{V}=N * a b s\left(\frac{d P_{p v}}{d V_{p v}}\right)
$$

VSC dynamic model in $a b c$ reference frame is obtained as:

$$
V_{I, a b c}=L_{i} \frac{d I_{i, a b c}}{d t}+R_{i} I_{i, a b c}+V_{2, a b c}
$$

Where:

$V_{I, a b c}=$ voltage at ac side of the VSC

$V_{2, a b c}=$ voltage at $\mathrm{PCC}$

$I_{i, a b c}=$ instantaneous current at abc

After transformation of (5) from $a b c$ reference frame to dq, reference frame the VSC dynamic equations become [3]:

$$
\begin{aligned}
& \frac{d I_{i d}}{d t}=-\frac{R_{i}}{L_{i}} I_{i d}+\omega I_{i q}+\frac{V_{i d}-V_{2 d}}{L_{i}} \\
& \frac{d I_{i q}}{d t}=-\frac{R_{i}}{L_{i}} I_{i q}-\omega I_{i d}+\frac{V_{i q}-V_{2 q}}{L_{i}}
\end{aligned}
$$

Where:

$V_{i, d q}=$ voltage at ac side of the VSI

$V_{2, d q}=$ voltage at the PCC

$I_{i, d q}=$ instantaneous current in dq frame.

$$
\begin{aligned}
& V_{i d}=\frac{\sqrt{3}}{\sqrt[2]{2}} V_{p v}\left(m_{a} \cos \delta\right)=\frac{\sqrt{3}}{\sqrt[2]{2}} V_{p v} U_{d} \\
& V_{i q}=\frac{\sqrt{3}}{\sqrt[2]{2}} V_{p v}\left(m_{a} \sin \delta\right)=\frac{\sqrt{3}}{\sqrt[2]{2}} V_{p v} U_{q}
\end{aligned}
$$

Where:

$U_{d}=m_{a} \cos \delta$

$U_{q}=m_{a} \sin \delta$

$V_{p v}=$ voltage at PV side of VSI

$m_{a}=$ PWM modulation index

$\delta=$ phase angel for firing of IGBTs of VSI inverter

The active and reactive powers at the PCC in the $a b c$ reference frame are obtained as:

$$
P_{2}=\frac{3}{2}\left(V_{2 d} I_{i d}+V_{2 q} I_{i q}\right)
$$

$$
=V_{2 a} I_{i a}+V_{2 b} I_{i b}+V_{2 c} I_{i c}
$$

$$
\begin{aligned}
Q_{2}= & \frac{3}{2}\left(V_{2 q} I_{i d}-V_{2 d} I_{i q}\right)=\frac{1}{\sqrt{3}}\left[V_{2 a}\left(I_{i b}-I_{i c}\right)\right. \\
& \left.+V_{2 b}\left(I_{i c}-I_{i a}\right)+V_{2 c}\left(I_{i a}-I_{i b}\right)\right]
\end{aligned}
$$

A $\mathrm{d}-\mathrm{q}$ axis power-based definition of VSC dynamics is provided only to model the ultimate control theory by calculating control variables. The instantaneous active power $\left(P_{2}\right)$ and reactive power $\left(Q_{2}\right)$ at PCC in $d$ - $q$ reference frame:

$$
\begin{aligned}
& P_{2}=\frac{3}{2}\left(V_{2 d} I_{i d}+V_{2 q} I_{i q}\right) \\
& Q_{2}=\frac{3}{2}\left(V_{2 q} I_{i d}-V_{2 d} I_{i q}\right)
\end{aligned}
$$

From (18), the instantaneous currents are obtained as:

$$
\begin{aligned}
& I_{i d}=\frac{2}{3}\left(\frac{P_{2} V_{2 d}+Q_{2} V_{2 q}}{V_{2}^{2}}\right) \\
& I_{i q}=\frac{2}{3}\left(\frac{P_{2} V_{2 q}-Q_{2} V_{2 d}}{V_{2}^{2}}\right)
\end{aligned}
$$

The voltage components $V_{2 d}, V_{2 q}$ and $I_{i d}, I_{i q}$ are obtained from the phase voltage and current components in the stationary frame as:

$$
\begin{aligned}
V_{2 d} & =\frac{1}{\sqrt{3}}\left(V_{2 b}-V_{2 c}\right) \\
I_{i d} & =\frac{1}{\sqrt{3}}\left(I_{i b}-I_{i c}\right) \\
V_{2 q} & =\frac{2}{3} V_{2 a}-\frac{1}{3}\left(V_{2 b}+V_{2 c}\right) \\
I_{i q} & =\frac{2}{3} I_{i a}-\frac{1}{3}\left(I_{i b}+I_{i c}\right)
\end{aligned}
$$

By substituting these $I_{i d}$ and $I_{i q}$ values to (13) and (14), the following differential equations are obtained in terms of $P_{2}$ and $Q_{2}$ as:

$$
\begin{aligned}
& \frac{d P_{2}}{d t}=-\frac{R_{i}}{L_{i}} P_{2}-\omega Q_{2}+\frac{U_{q}}{L_{i}} \\
& \frac{d Q_{2}}{d t}=-\frac{R_{i}}{L_{i}} Q_{2}+\omega P_{2}+\frac{U_{p}}{L_{i}}
\end{aligned}
$$

Where the control parameters are:

$$
\begin{aligned}
& U_{q}=\frac{3}{2}\left[V_{i d} V_{2 d}+V_{i q} V_{2 q}-\left(V_{2 d}{ }^{2}+V_{2 q}{ }^{2}\right)\right] \\
& U_{p}=\frac{3}{2}\left(V_{i d} V_{2 q}-V_{i q} V_{2 d}\right)
\end{aligned}
$$


At the PV side of the VSC, the dc link capacitor voltage shows another dynamic relation as (where switching losses is assumed to be neglected):

$$
C_{p v} \frac{d V_{p v}}{d t}=I_{p v}-\frac{P_{i}}{V_{p v}}
$$

Which can be rewritten as:

$$
\frac{d V_{p v}}{d t}=\frac{1}{C_{p v} V_{p v}}\left(p_{p v}-P_{i}\right)
$$

Equations (21), (22) and (25) are used to construct the dynamic model for the proposed VSC based grid integrated PV system. During system dynamic operation, the operating frequency is achieved by a droop control strategy as shown in (26).

$$
f-f_{0}=-R_{\text {droop }}\left(P_{i}-P_{p v}\right)
$$

Where $f_{0}=$ nominal operating frequency.

Power components are independent of $a b c$ to d-q coordinate transformation for the controller design [19]. Equation (17) is considered to calculate the power components directly from $a b c$ coordinate voltage and current at PCC. For PI controller small signal stability analysis, the method is outlined below:

Small signal stability analysis for Multivariable VSC model.

In time domain, the VSC dynamics can be represented in small signal terms as:

$$
\begin{aligned}
& \frac{d \Delta P_{2}(t)}{d t}=-\frac{R_{i}}{L_{i}} \Delta P_{2}(t)-\omega \Delta Q_{2}(t)+\Delta U_{q}(t) \\
& \frac{d \Delta Q_{2}(t)}{d t}=-\frac{R_{i}}{L_{i}} \Delta Q_{2}(t)+\omega \Delta P_{2}(t)+\Delta U_{p}(t)
\end{aligned}
$$

Above two equations can be transformed in frequency domain and rewritten as:

$$
\begin{aligned}
& \left(s+\frac{R_{i}}{L_{i}}\right) \Delta P_{2}(s)+\omega \Delta Q_{2}(s)=\Delta U_{q}(s) \\
& \left(s+\frac{R_{i}}{L_{i}}\right) \Delta Q_{2}(s)-\omega \Delta P_{2}(s)=\Delta U_{p}(s)
\end{aligned}
$$

The matrix representation of (29) and (30) is obtained as:

$$
\left[\begin{array}{l}
\Delta P_{2} \\
\Delta Q_{2}
\end{array}\right]=\left[\begin{array}{cc}
\frac{a_{1}}{a_{1}^{2}+a_{2}^{2}} & -\frac{a_{2}}{a_{1}^{2}+a_{2}^{2}} \\
\frac{a_{2}}{a_{1}^{2}+a_{2}^{2}} & \frac{a_{1}}{a_{1}^{2}+a_{2}^{2}}
\end{array}\right]\left[\begin{array}{l}
\Delta U_{q} \\
\Delta U_{p}
\end{array}\right]
$$

Where:

$$
a_{1}=s+\frac{R_{i}}{L_{i}}
$$

$$
a_{2}=\omega
$$

Equation (31) represents a multivariable dynamic model as described in [5]. From (31) for active power control only, we can write:

$$
\Delta P_{2}=\frac{a_{1}}{a_{1}^{2}+a_{2}^{2}} \Delta U_{q}
$$

From the PI control design, it can be derived:

$$
\begin{aligned}
& \left(\Delta P_{2}{ }^{*}-\Delta P_{2}\right)\left(K_{p 1}+\frac{K_{i 1}}{S}\right)+K_{p v}\left(\Delta V_{p v}{ }^{*}-\Delta V_{p v}\right) \\
& =\Delta U_{q}
\end{aligned}
$$

On substitution and simplification, the following equation is obtained:

$$
\begin{aligned}
\Delta P_{2}= & \frac{G_{i 1} G_{p 1}}{1+G_{i 1} G_{p 1}} \Delta P_{2}{ }^{*} \\
& +\frac{G_{i 1} K_{p v}}{1+G_{i 1} G_{p 1}}\left(\Delta V_{p v}{ }^{*}-\Delta V_{p v}\right)
\end{aligned}
$$

Where:

$$
\begin{aligned}
G_{11} & =\frac{a_{1}}{a_{1}{ }^{2}+a_{2}^{2}} \\
G_{p 1} & =K_{p 1}+\frac{K_{i 1}}{s}
\end{aligned}
$$

The gains have been determined to minimum overshoot which ensures the stability. The frequency response has been analyzed to validate above mentioned stability of the closed loop path. By letting $s=j c$, the open loop SISO transfer function $G_{11}(s) \cdot G_{p 1}(s)$ is mapped into (37).

$$
\begin{aligned}
& G_{11}(j \omega) G_{p 1}\left(j \omega_{s}\right) \\
& =\frac{\left(b_{1} b_{2}-b_{3} b_{4}\right)+j\left(b_{3} b_{2}-b_{1} b_{4}\right)}{{b_{2}}^{2}-b_{4}{ }^{2}}
\end{aligned}
$$

Where:

$$
\begin{aligned}
& b_{1}=K_{i 1} \frac{R_{i}}{L_{i}}-K_{p 1} \omega^{2} \\
& b_{2}=\left(\frac{R_{i}}{L_{i}}\right)^{2}+\omega_{s}^{2}+\omega^{2} \\
& b_{3}=K_{i 1}+K_{p 1} \frac{R_{i}}{L_{i}} \\
& b_{4}=2\left(\frac{R_{i}}{L_{i}}\right) \omega
\end{aligned}
$$




\section{METHODOLODY}

\section{A. Fuzzy Logic Controller}

Fuzzy Logic Controller are based on fuzzy set theory [20]. As stated by [11, 20], FLC commonly consist of four components that are consist of fuzzification, rule base, inference engine and defuzzification. The block diagram of the FLC is shown in Fig. 2.

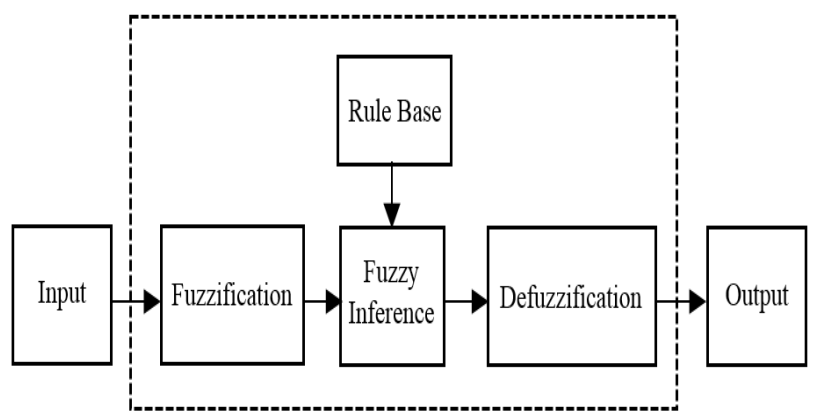

Fig. 2. Block diagram of Fuzz Logic Controller

Generally, there are two inputs on the FLC which are error (e) value and changes in error $(\Delta e)$. These inputs are measured from the value of current and voltage of the output of PV system. The value is defined in (39) and (40).

$$
\begin{aligned}
& e(k)=\frac{P(k)-P(k-1)}{V(k)-V(k-1)} \\
& \Delta e(k)=e(k)-e(k-1)
\end{aligned}
$$

Where:

$e(k)=$ error value

$(k)=$ sampling time

$e(k-1)=$ error value at $(k-1)$ sampling time

$\Delta e(k)=$ changes in error

$\mathrm{P}=$ value of power

$\mathrm{V}=$ value of voltage

The rules explaining the FLC operation are indicate as linguistic variables that defined as fuzzy sets. The linguistic variables are considerd as negative big (NB), negative small (NS), zero (ZO), positive small (PS), and positive big (PB). The shape of the membership functions that related to the FLC linguistic variable are frequently in trapezoidal or triangular shape or known as piece-wise linear functions. The form and number of the membership functions of each fuzzy logic inference mechanism and fuzzy set was originally choose based on trial and error method. Fig. 3 and Fig. 4 shown that the fuzzification of error value and changes in error. The defuzzification of the changes in the duty cycle values is shown in Fig. 5. Table 1 shown the rule based of FLC where the input are fuzzy sets of error $(e)$ and the change of error $(\Delta e)$.

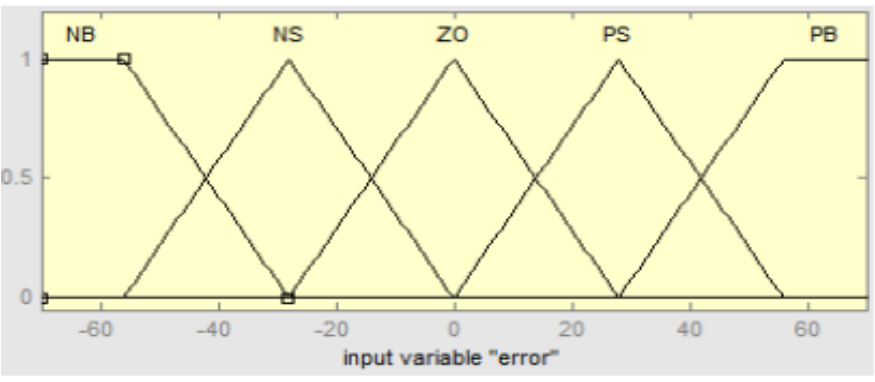

Fig. 3. Membership function plots for error $(e)$ [11]

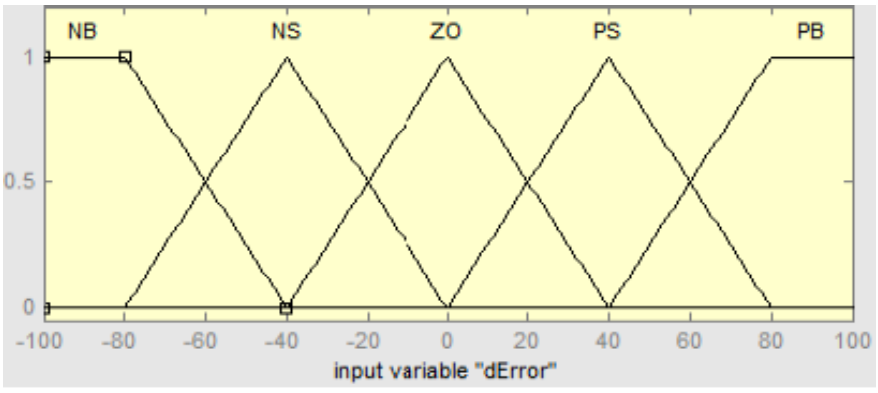

Fig. 4. Membership function plots for changes in error $(\Delta e)[11]$

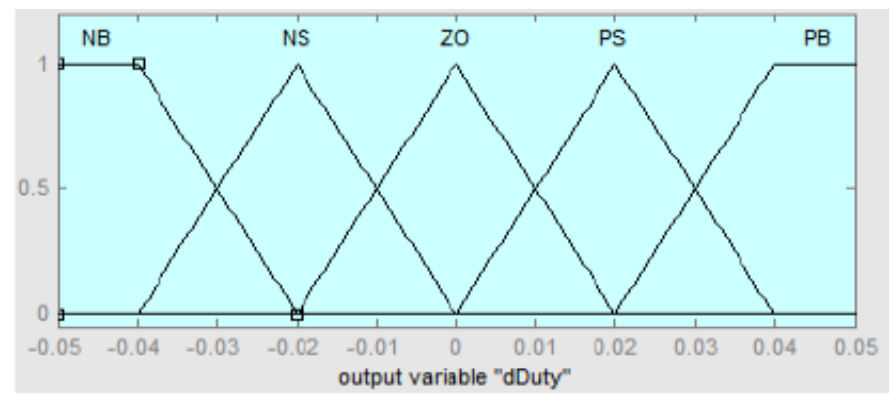

Fig. 5. Membership function plots for changes in duty cycle [11]

TABLE I

FUZZY RULE BASE

\begin{tabular}{c|ccccc}
\multicolumn{5}{c}{ FUZZY RULE BASE } \\
\hline \hline
\end{tabular}

\section{B. Microgrid System with Fuzzy Logic Controller and Conventional Controller}

A PV connected in microgrid system examples of MATLAB/Simulink R2018a (Fig. 1) is used for the simulation. Fig. 6 shows the main model of the system. The results of the performance comparing both controllers will be shown in Fig. 9 to Fig. 24.

Based on Fig. 6, it shows that there is fault, irradiance, VSC Controller and feeders. The simulation of the system was run accordingly based on each controller, with high loading and low loading with fixed irradiance, under a fault and with or without feeders. 


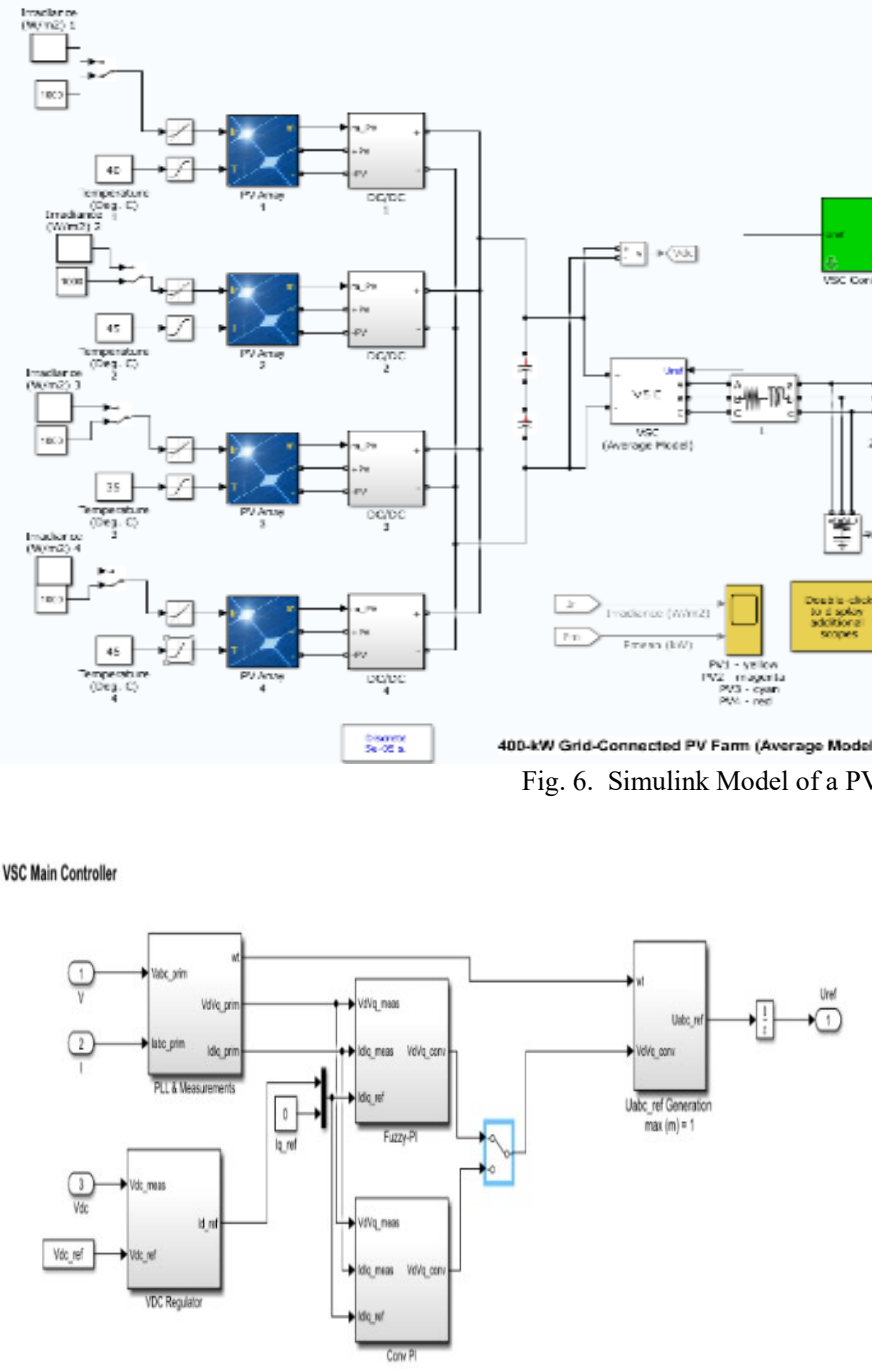

Fig. 7. Fuzzy Logic Controller

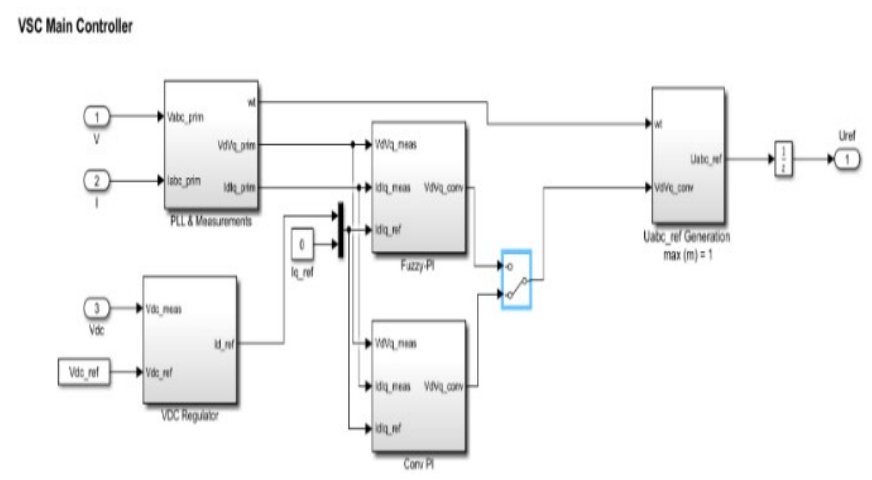

Fig. 8. Conventional Controller

For this paper, there are two types of controller under the VSC controller which are Fuzzy Logic controller (Fig. 7) and Conventional Controller (Fig. 8) to be simulate at each case which are with fixed irradiance, with variable irradiance, with fault, with loading feeder or without loading feeder.

\section{RESULT AND DISCUSSION}

The results of each cases using different controller will be shown in this topic.

1. With Fixed Irradiance, with Fault, at High Loading, with $8 \mathrm{~km}$ feeder at load.

- Fuzzy Logic Controller

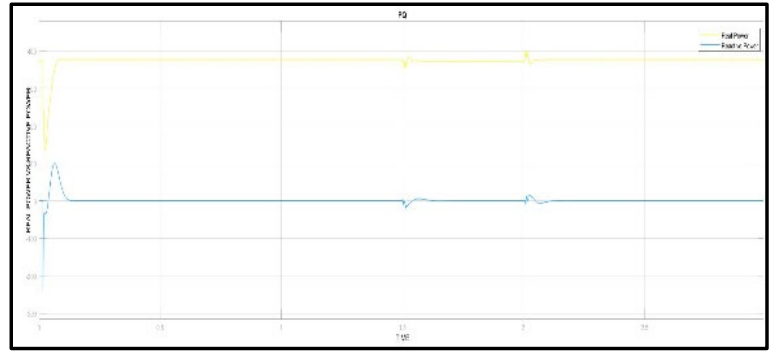

Fig. 9. Fuzzy Logic Controller

- Conventional Controller

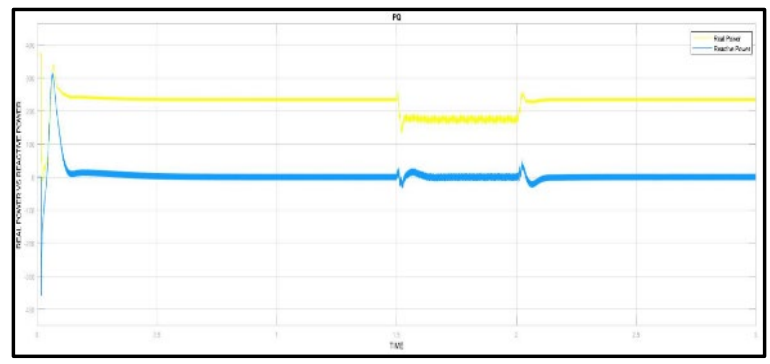

Fig. 10. Conventional Controller

It is observed from Fig. 9 that the Fuzzy Logic based controller has better Real and Reactive power compared to conventional controller from Fig. 10.

2. With Fixed Irradiance, with fault, at high loading without $8 \mathrm{~km}$ feeder at load. 
- Fuzzy Logic Controller

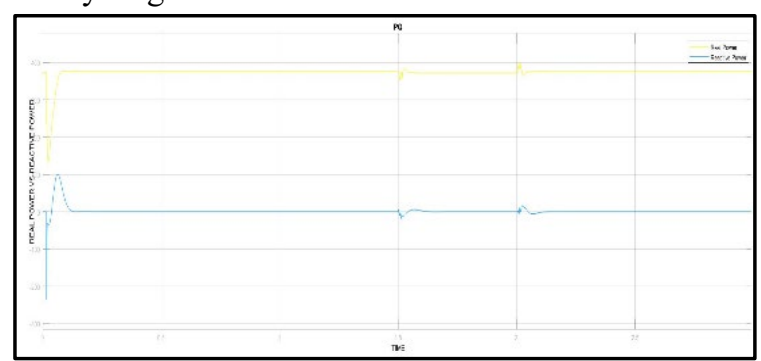

Fig. 11. Fuzzy Logic Controller

- Conventional Controller

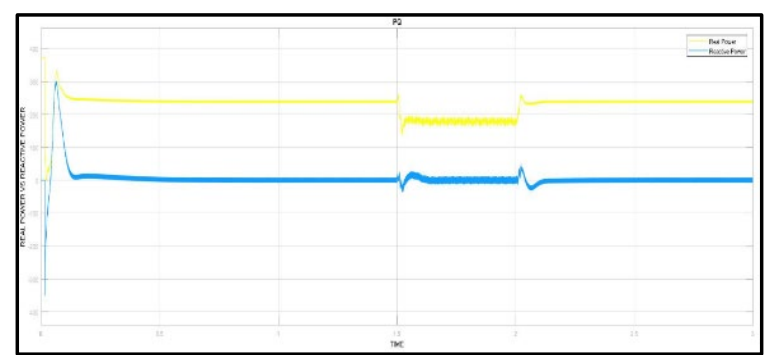

Fig. 12. Conventional Controller

It is observed from Fig. 11 that the Fuzzy Logic based controller has better Real and Reactive power compared to conventional controller from Fig. 12.

3. With Fixed Irradiance, with fault, at low loading with $8 \mathrm{~km}$ feeder at load.

- Fuzzy Logic Controller

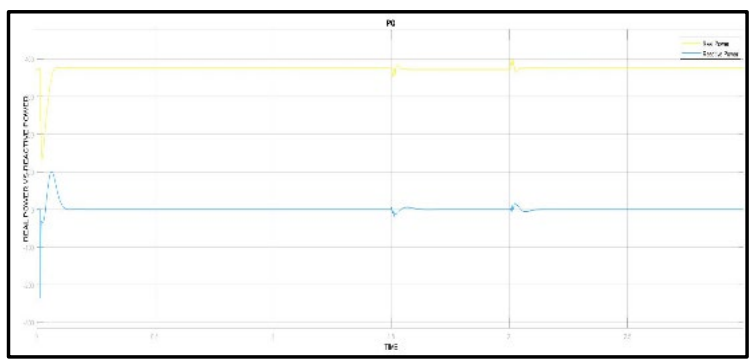

Fig. 13. Fuzzy Logic Controller

- Conventional Controller

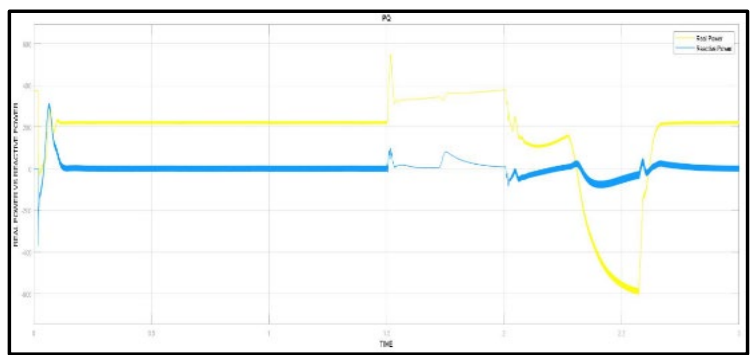

Fig. 14. Conventional Controller

It is observed from Fig. 13 that the Fuzzy Logic based controller has better Real and Reactive power compared to conventional controller from Fig. 14.
4. With Fixed Irradiance, with fault, at low loading without $8 \mathrm{~km}$ feeder at load.

- Fuzzy Logic Controller

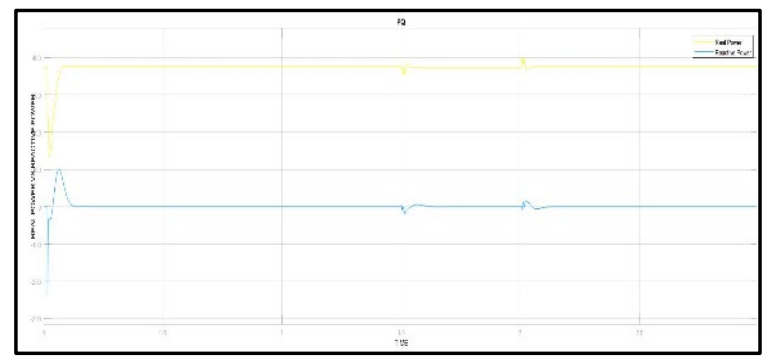

Fig. 15. Fuzzy Logic Controller

- Conventional Controller

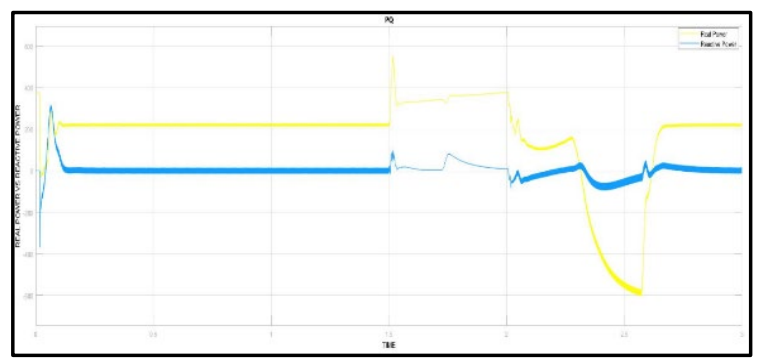

Fig. 16. Conventional Controller

It is observed from Fig. 15 that the Fuzzy Logic based controller has better Real and Reactive power compared to conventional controller from Fig. 16.

5. With Variable Irradiance, with fault, at high loading with $8 \mathrm{~km}$ feeder at load.

- Fuzzy Logic Controller

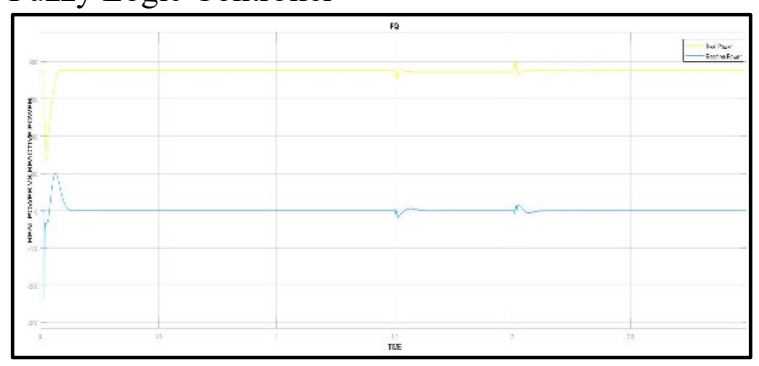

Fig. 17. Fuzzy Logic Controller

- Conventional Controller

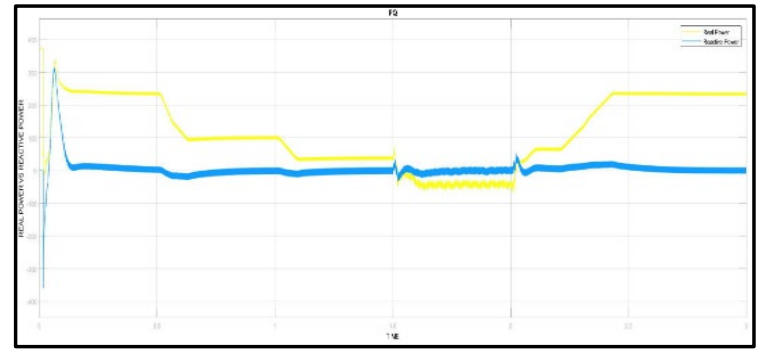

Fig. 18. Conventional Controller

It is observed from Fig. 17 that the Fuzzy Logic based controller has better Real and Reactive power compared to conventional controller from Fig. 18. 
6. With Variable Irradiance, with fault, at high loading, without $8 \mathrm{~km}$ feeder at load.

- Fuzzy Logic Controller

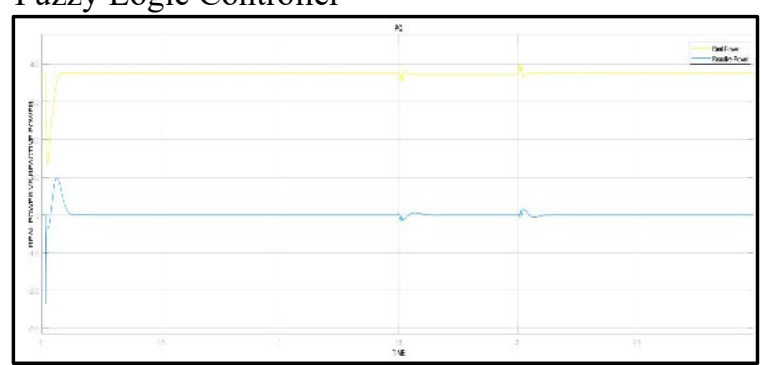

Fig. 19. Fuzzy Logic Controller

- Conventional Controller

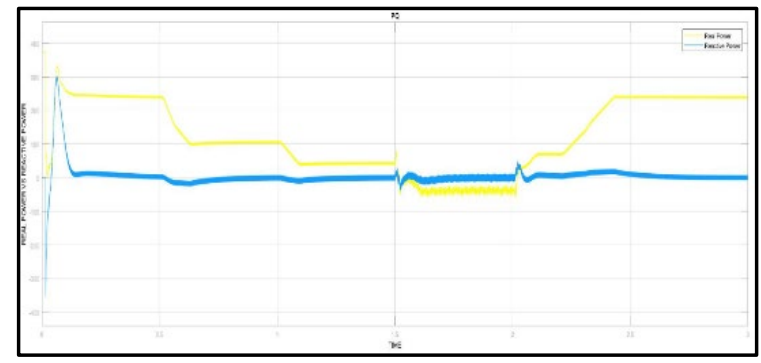

Fig. 20. Conventional Controller

It is observed from Fig. 19 that the Fuzzy Logic based controller has better Real and Reactive power compared to conventional controller from Fig. 20.

7. With Variable Irradiance, with fault, at low loading, with $8 \mathrm{~km}$ feeder at load.

- Fuzzy Logic Controller

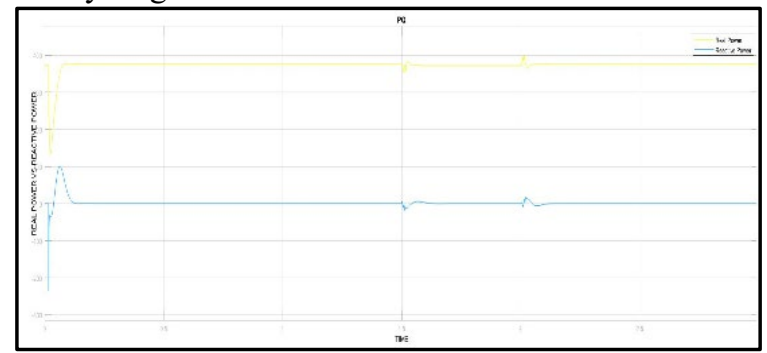

Fig. 21. Fuzzy Logic Controller

- Conventional Controller

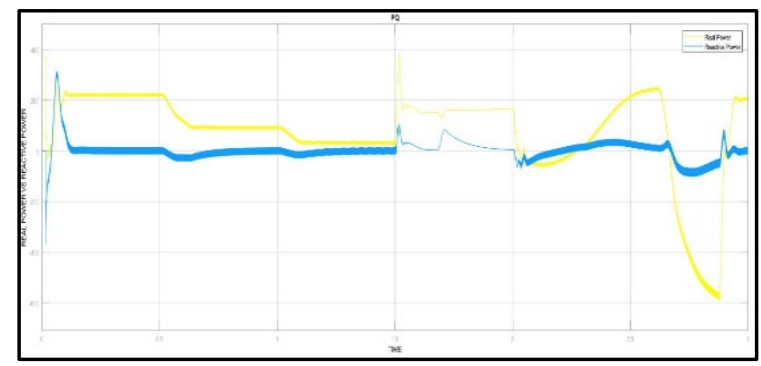

Fig. 22. Conventional Controller
It is observed from Fig. 21 that the Fuzzy Logic based controller has better Real and Reactive power compared to conventional controller from Fig. 22.

8. With Variable Irradiance, with fault, at low loading, without $8 \mathrm{~km}$ feeder at load.

- Fuzzy Logic Controller

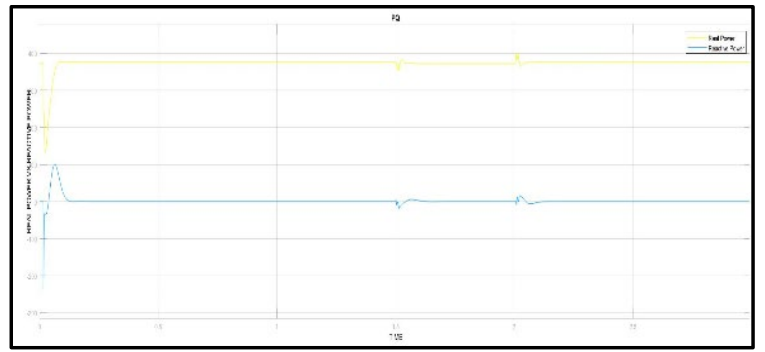

Fig. 23. Fuzzy Logic Controller

- Conventional Controller

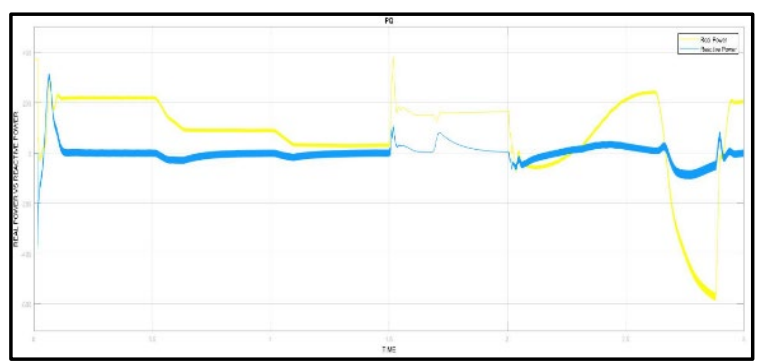

Fig. 24. Conventional Controller

It is observed from Fig. 23 that the Fuzzy Logic based controller has better Real and Reactive power compared to conventional controller from Fig. 24.

\section{CONCLUSION}

This paper presents a performance comparison of real and reactive power flow in microgrid through PV system using both controller which are Fuzzy logic based and Conventional controller. The objective of this paper is to analyse the controller performance of conventional controller and the proposed one. Different types of controller will give different results based on each case in the PV system. Fuzzy logic controller gives more stable and efficient results in the simulation compared to conventional controller.

Future recommendations can be made in this paper where using fuzzy logic controller is more stable and efficient compared to conventional controller.

\section{ACKNOWLEDGMENT}

The author and researchers sincerely thank IRMI, 600-IRMI/DANA 5/3/LESTARI (0169/2016), and UiTM for providing lab facility and the fund to conduct this research smoothly.

\section{REFERENCES}

[1] M. Rouse, "What is electrical power management system (EPMS)? - Definition from WhatIs.com." [Online]. Available: https://whatis.techtarget.com/definition/electrical-powermanagement-system-EPMS. [Accessed: 31-Oct-2019]. 
[2] C. Natesan, S. K. Ajithan, S. Chozhavendhan, and A. Devendiran, "Power Management Strategies In Microgrid:A Survey," Int. J. Renew. Energy Res., vol. 5, no. 2, pp. 334-340, 2015.

[3] S. Saravanan and S. Thangavel, "A Simple Power Management Scheme with Enhanced Stability for a Solar PV/Wind/Fuel Cell/Grid Fed Hybrid Power Supply Designed for Industrial Loads," J. Electr. Comput. Eng., vol. 2014, pp. 1-18, 2014.

[4] N. K. Choudhary, S. R. Mohanty, and R. K. Singh, "Active and reactive power management in microgrid: Analysis in grid connected and Islanded mode of operation," Indian J. Sci. Technol., vol. 9, no. 21, 2016.

[5] C. Wan, J. Zhao, Y. Song, Z. Xu, J. Lin, and Z. Hu, "Photovoltaic and solar power forecasting for smart grid energy management," CSEE J. Power Energy Syst., vol. 1, no. 4, pp. 38-46, 2016.

[6] F. Colas, D. Lu, V. Lazarov, B. François, and H. Kanchev, "Energy management and power planning of a microgrid with a PV-based active generator for Smart Grid Applications," IEEE Trans. Ind. Electron., vol. 58, no. 10, pp. 4583-4592, 2011.

[7] A. Kaur, "Comparison between Conventional PID and Fuzzy Logic Controller for Liquid Flow Control: Performance Evaluation of Fuzzy Logic and PID Controller by Using MATLAB / Simulink," Int. J. Innov. Technol. Explor. Eng., vol. 1, no. 1, pp. 84-88, 2012.

[8] G. Balasubramanian and S. Singaravelu, "Fuzzy logic controller for the maximum power point tracking in photovoltaic system," Int. J. Comput. Appl., vol. 41, no. 12, pp. 22-28, 2012, doi: 10.5120/5594-7840.

[9] B. Mondal, A. Billaha, B. Roy, and R. Saha, "Performance Comparison of Conventional PID and Fuzzy Logic Controller in the Field of Over Headed Water Level Control System," Int. J. Comput. Sci. Eng., vol. 4, no. 6, pp. 76-81, 2016.

[10] O. Guenounou, B. Dahhou, and F. Chabour, "Adaptive fuzzy controller based MPPT for photovoltaic systems," Energy Convers. Manag., vol. 78, pp. 843-850, 2014, doi: 10.1016/j.enconman.2013.07.093.

[11] E. N. Yaqin, A. G. Abdullah, D. L. Hakim, and A. B. D. Nandiyanto, "MPPT based on Fuzzy Logic Controller for Photovoltaic System using PSIM and Simulink," IOP Conf. Ser. Mater. Sci. Eng., vol. 288, no. 1, 2018, doi: 10.1088/1757899X/288/1/012066.

[12] X. Li, H. Wen, Y. Hu, and L. Jiang, "A novel beta parameter based fuzzy-logic controller for photovoltaic MPPT application," Renew. Energy, vol. 130, pp. 416-427, 2019, doi: 10.1016/j.renene.2018.06.071.

[13] K. Loukil, H. Abbes, H. Abid, M. Abid, and A. Toumi, "Design and implementation of reconfigurable MPPT fuzzy controller for photovoltaic systems," Ain Shams Eng. J., no. xxxx, 2019, doi: 10.1016/j.asej.2019.10.002.

[14] N. Khaehintung, P. Sirisuk, and W. Kurutach, "A novel ANFIS controller for maximum power point tracking in photovoltaic systems," Proc. Int. Conf. Power Electron. Drive Syst., vol. 2, no. 1, pp. 833-836, 2003, doi: 10.1109/PEDS.2003.1283074.

[15] A. Chouder, , F. Guijoan2, and S. Silvestre, A. Chouder, and S. Silvestre, "Simulation of fuzzy-based MPP tracker and performance comparison with perturb \& observe method," Rev. des Energies Renouvelables, vol. Vol. 11, no. N4, pp. 577 - 586, 2008.

[16] M. A. Hannan, Z. A. Ghani, M. M. Hoque, P. J. Ker, A. Hussain, and A. Mohamed, "Fuzzy logic inverter controller in photovoltaic applications: Issues and recommendations," IEEE Access, vol. 7, no. c, pp. 24934-24955, 2019, doi: 10.1109/ACCESS.2019.2899610.

[17] N. Patcharaprakiti, S. Premrudeepreechacharn, and Y. Sriuthaisiriwong, "Maximum power point tracking using adaptive fuzzy logic control for grid-connected photovoltaic system," Renew. Energy, vol. 30, no. 11, pp. 1771-1788, 2005, doi: 10.1016/j.renene.2004.11.018.

[18] N. Pandiarajan and R. Muthu, "Mathematical modeling of photovoltaic module with Simulink," 2011 1st Int. Conf. Electr. Energy Syst. ICEES 2011, no. February 2011, pp. 258-263, 2011.

[19] Ahmadreza Tabesh; Reza Iravani, "Paper 1: Multivariable Dynamic Model \& Robust Control of a Voltage-Source Converter for Power System Applications Introduction and motivation VSC dynamic model Multivariable Controller Design for VSC Application Example Conclusion."

[20] F. Chekired, C. Larbes, D. Rekioua, and F. Haddad, "Implementation of a MPPT fuzzy controller for photovoltaic systems on FPGA circuit," Energy Procedia, vol. 6, pp. 541-549, 2011, doi: 10.1016/j.egypro.2011.05.062.

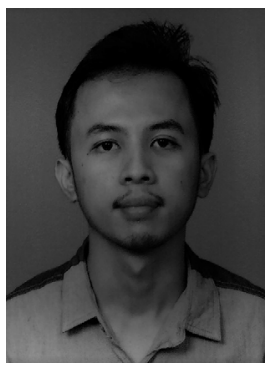

Ameerul Aiman Bin Jeman was born in Kuching, Sarawak in 1994. Obtaining his Diploma of Electrical Engineering (Electronics) in 2015 and Bachelor of Electrical Engineering in 2018 both from Universiti Teknologi Mara, Malaysia. He is currently studying for Master of Science (Electrical Engineering) at Universiti Teknologi Mara, Shah Alam and doing research focusing on Solar PV in Microgrid Power System.

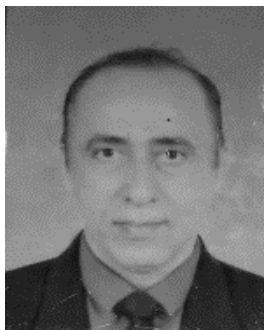

Professor Madya Dr. Naeem M.S Hannoon (BSc Distinction, MSc, PhD, IEE, IASTED) has over 20 years' experience in both academic and industrial lines. He worked as Electrical Engineer for 5 years in Kuwait Thermal Power Plant and 2 years as a site engineer in Malaysia and participated in various projects of designing and commissioning of power Substations. Dr. Naeem is currently attached to Faculty of Electrical Engineering in University Technology Mara, Malaysia.

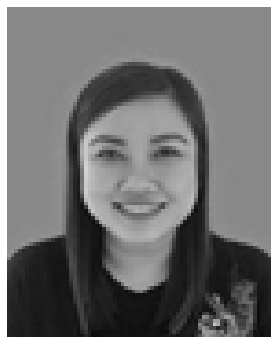

Sharon Serenade Anak Gerang was born in Limbang, Sarawak, in 1994. She obtained Diploma of Electrical Engineering (Electronics) in 2015 Bachelor of Electrical Engineering at Universiti Teknologi Mara, Shah Alam Malaysia in 2018. She is currently studying for Master of Science (Electrical Engineering) at Universiti Teknologi Mara, Shah Alam and doing research focusing on Solar PV in Microgrid Power System. 